Full Length Article

\title{
The chicken eggshell calcium oxide ultrasonically dispersed over lignite coal fly ash-based cancrinite zeolite support as a catalyst for biodiesel production
} \author{
Ljiljana V. Mojovićc ${ }^{c}$, Miroslav V. Stankovića, Vlada B. Veljkovićc ${ }^{\text {b, }}$, \\ ${ }^{\text {a }}$ University of Belgrade, Institute of Chemistry, Technology and Metallurgy, Njegoševa 12, 11000 Belgrade, Serbia \\ ${ }^{\mathrm{b}}$ University of Niš, Faculty of Technology, Bulevar oslobodjenja 124, 16000 Leskovac, Serbia \\ ${ }^{\mathrm{c}}$ University of Belgrade, Faculty of Technology and Metallurgy, Karnegijeva 4, 11000 Belgrade, Serbia \\ ${ }^{\mathrm{d}}$ The Serbian Academy of Sciences and Arts, Knez Mihailova 35, 11000 Belgrade, Serbia
}

Stefan M. Pavlović a, Dalibor M. Marinkovića ${ }^{\mathrm{a}}$, Milan D. Kostić ${ }^{\mathrm{b}}$, Davor R. Lončarević ${ }^{\mathrm{a}}$,

\section{A R T I C L E I N F O}

\section{Keywords:}

Lignite coal fly ash

Cancrinite

Chicken eggshell

Ultrasound-assisted dispersion

Supported catalyst

Biodiesel

\begin{abstract}
A B S T R A C T
Lignite coal fly ash (FA) from a domestic thermal power plant was converted into a pure cancrinite zeolitic material $\left(\mathrm{ZM}_{\mathrm{FA}}\right)$ using a novel, custom-made, rotating autoclave reactor system by a short-term alkali activation process. The obtained $\mathrm{ZM}_{\mathrm{FA}}$ was used as catalyst support of calcium oxide as an active component derived from waste chicken eggshells (ES). The $\mathrm{ZM}_{\mathrm{FA}}$ supported calcium oxide catalyst $\left(x \mathrm{CaO} / \mathrm{ZM}_{\mathrm{FA}}\right)$ was synthesized by means of the ultrasound-assisted method. The influence of different concentrations of dispersed calcium oxide ( $x$ $=5-20 \mathrm{wt} \%$ ) over $\mathrm{ZM}_{\mathrm{FA}}$ and thermal treatment at different temperatures $\left(450-600{ }^{\circ} \mathrm{C}\right)$ were studied. The structural and morphological characterization showed that the original cancrinite structure was preserved. The basicity and textural properties indicated the presence of strong active sites in a well-defined pore network suitable for the reactions of bulky organic compounds such as triacylglycerols (TAGs). The highest activity ( $96.5 \%$ of fatty acid methyl esters) in the methanolysis of sunflower oil was achieved with the $20 \mathrm{CaO} / \mathrm{ZM}_{\mathrm{FA}}$ catalyst under reaction conditions: temperature of $60^{\circ} \mathrm{C}$, methanol/oil molar ratio of $12: 1$, catalyst concentration of $4 \mathrm{wt} \%$, and reaction time of $2 \mathrm{~h}$. It was found that the optimal calcination temperature of the catalyst precursor was $550{ }^{\circ} \mathrm{C}$. At calcination temperatures above $550{ }^{\circ} \mathrm{C}$, the melting of the glassy phase became more intense whereby the molten phase partially reacted with calcium oxide forming the catalytically inactive calcium silicate compounds (wollastonite, larnite, etc.). The rate constants of the two tested kinetic models were correlated with the concentrations of active calcium oxide. The MRPD of both models was low indicating their reliability.
\end{abstract}

\section{Introduction}

Fly ash (FA), an industrial waste mainly disposed at open-sites [1], generated by bituminous, sub-bituminous, and lignite coals combustion in thermal power plants, represents one of the most complex anthropogenic materials containing hazardous substances for humans and the environment [2]. The disposal of FA at open-sites is not environmentally friendly due to its leachability, radioactivity, and toxicity, which may cause serious contamination in soil, natural water sources, and air [3]. Depending on the type of coal, various types of FA (silica, silica-alumina, and silica-calcium ash) are formed. Each type contains a number of minerals and mineral groups that affect the way how it is used, treated, and converted into value-added products [4]. Currently, the application of FA is focused on their use in the cement industry, industrial construction materials, agriculture for soil amendment or fertilization, and road construction $[5,6]$. FA is considered as a very promising material for obtaining various types of zeolites for the application in many sustainable processes [7], particularly in sustainable chemistry in the fields of renewable energy and environmental improvement [8,9], as well as highly efficient catalysts $[10,11]$, catalyst supports [12], adsorbents [13], and ion-exchangers [14]. The various synthesis methods, reaction conditions, and reactor types were used for obtaining zeolitic materials. The most important zeolitization variables that influenced the final properties of the synthesized zeolites include crystallization

\footnotetext{
* Corresponding author.

E-mail addresses: veljkovicvb@yahoo.com, veljkovic@tf.ni.ac.rs (V.B. Veljković).
} 


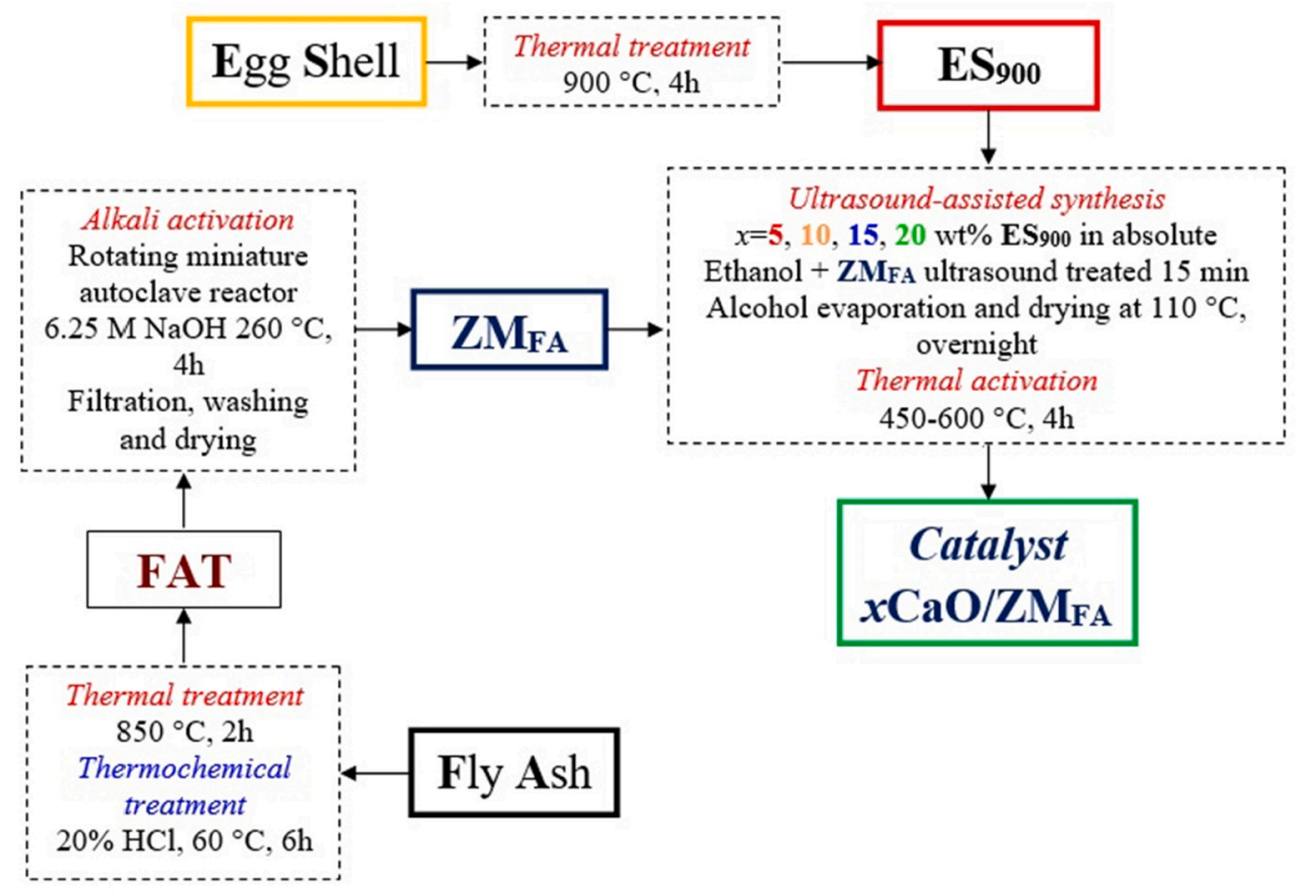

Fig. 1. The scheme of the catalyst synthesis procedure.

temperature, the concentration of alkali agent, the synergism of alkali agents [15], addition of alkali aluminate activators, change in the crystallization medium [8], reaction and aging period [16,17], type of reactor [18], and agitation system $[19,20]$. One of the more important parameters is how the reactants are mixed in the reactor during the zeolitization. Compared with the common contact agitation reactor, where the shear rate plays an important role [19], contactless mixing of the reactants in some cases forms pure zeolite phases under moderate reaction conditions [21]. Many studies have been focused on the use of FA-based zeolites as catalysts or catalyst supports for biofuels production from various feedstocks [10,21-24]. The advantages of heterogeneously catalyzed biodiesel production, such as simple green transesterification, mild reaction conditions, fatty acid methyl esters (FAMEs) yield, and reusability, lead to overcome of many disadvantages of the homogeneously catalyzed process (difficulties in the purification process, corrosion, metal leaching, and soap formation) [25-27]. In order to improve catalyst performance and prevent excessive leaching of active species and blocking of the catalyst with reaction by-products, appropriately supported catalysts should be developed [28]. The supported base catalysts synthesized from solid waste, such as FA and shells (eggs, oysters, and clams) with a suitable porous structure (mesoporosity, uniform pore size, well-defined pore shape) are of particular interest for biodiesel production [29]. Different silicate supports [29] and co-metals [30] could improve the activity of calcium oxide. Mansir et al. [31] reported that transition bimetallic mixed oxides added to the $\mathrm{CaO}$ surface reduced leaching of the catalytic active site of calcium phases $\left(\mathrm{Ca}^{2+}\right)$ providing high biodiesel yield in five consecutive cycles. Foroutan et al. [32] studied the behavior of $\mathrm{CaO} @ \mathrm{MgO}$ nanocatalyst in the biodiesel production from waste edible oil and showed its good stability and high biodiesel conversion yield (98.4\%). Dehghani and Haghighi [29] reported that altering of Si/Ce molar ratio in mesoporous silica support (MCM-41) in ultrasonically dispersed $\mathrm{MgO}$ over a ceriumdoped MCM-41 nanocatalyst considerably enhanced the conversion of acidic oils in biodiesel production. Wu et al. [33] confirmed the beneficial effect of phyllosilicate clay (bentonite) in the base-catalyzed methanolysis of TAG by promoting the transformation of the catalytically active species and lowering the soap formation in the side reaction. All the above-mentioned researches confirmed an affirmative synergism of the silicate-based support and alkaline earth metal species as dopants, in preventing the rapid deactivation due to the action of contaminants and leaching. The researchers' efforts to develop novel, highperformance catalysts based on waste materials for biodiesel production are in accordance with the principles of sustainable development.

The main goal of the present study is to recycle solid waste into value-added, high active biodiesel supported catalyst using environmentally friendly and economically favorable approaches. Lignite coal FA from a Serbian thermal power plant was converted into cancrinite zeolitic material using a novel, original, custom-made rotating autoclave reactor in a one-step process under moderate zeolitization conditions. Calcium oxide derived from chicken eggshell (ES) was dispersed over cancrinite zeolite support using a time-saving, ultrasound-assisted method to synthesize an active supported catalyst with original zeolite structure and well-distributed active centers. In addition, the key catalyst synthesis parameters were evaluated and optimized to obtain an effective catalyst for biodiesel production. To explain the transformation of wastes to the useful catalyst, all synthesized samples were comprehensively characterized, including crystallography, morphology, textural, and structural analysis. Finally, the rate constants of two different kinetic models of the methanolysis of sunflower oil were determined and correlated with the concentrations of active calcium oxide.

\section{Materials and methods}

\subsection{Materials}

FA from the electrostatic precipitator was collected in the Serbian Thermal Power Plant (Nikola Tesla "B", Obrenovac). Raw chicken ES were gathered from the household. The chemical compositions of FA and ES are presented in Supplement (Table S1).

The acid treatment of FA was done using $20 \%$ hydrochloric acid (Lachner, Czech Republic), whereas sodium hydroxide pellets (Emsure, ACS Reagents, Germany) were used as an alkali activator. A suspension of cancrinite zeolitic material $\left(\mathrm{ZM}_{\mathrm{FA}}\right)$ was made using absolute ethanol (Gram, Belgrade). All chemicals were of analytical grade. Commercial sunflower oil (Dijamant a.d., Zrenjanin, Serbia) and methanol (HPLC 


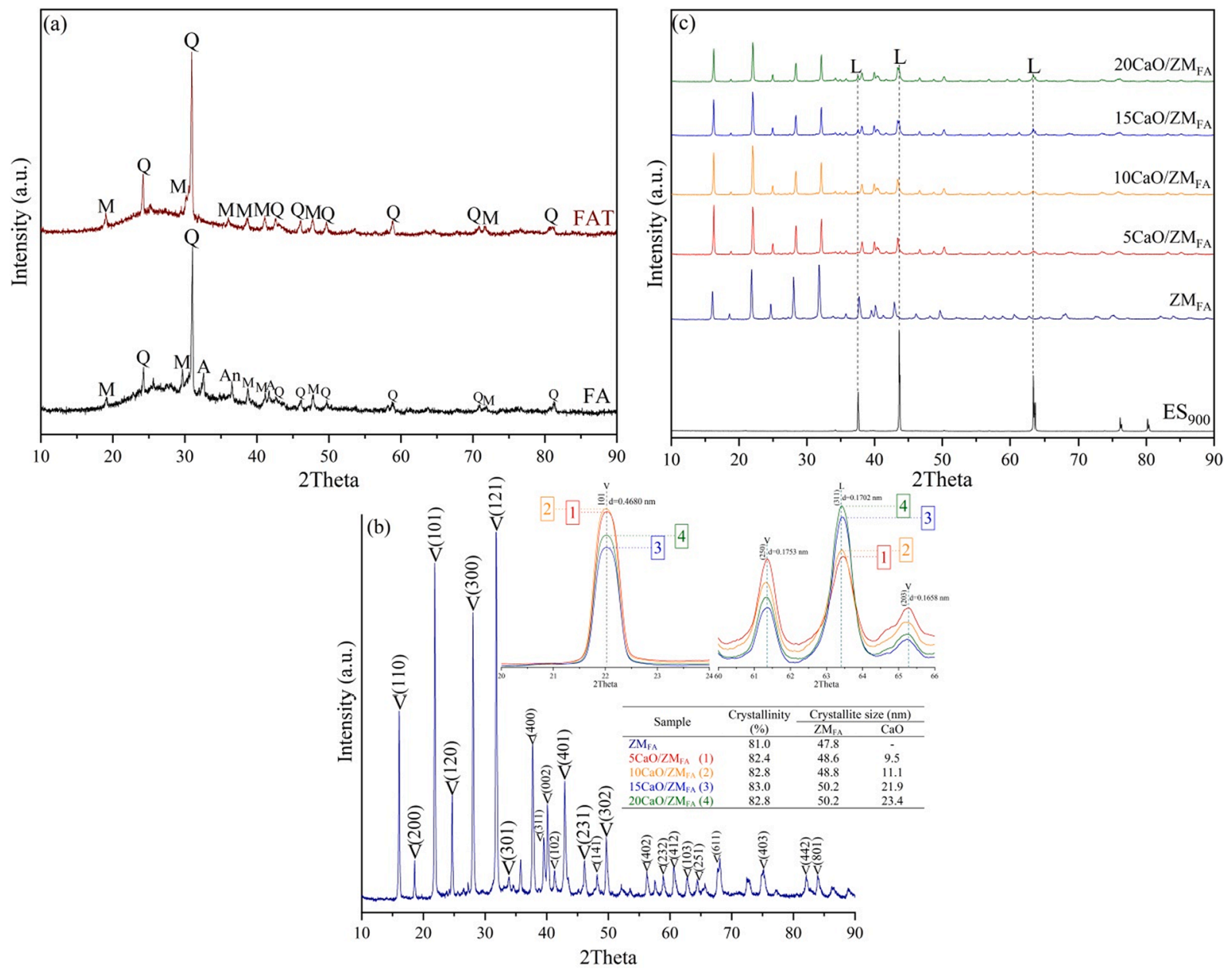

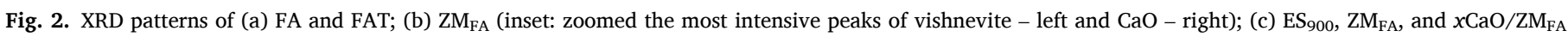
catalysts $(x=5,10,15$, and $20 \mathrm{wt} \%$ of $\mathrm{CaO}$ ) (A - aragonite, An - anorthite, L - lime, M - mullite, Q - quartz, V - vishnevite).

grade, J. T. Baker) were used to perform catalytic tests.

\subsection{Catalyst preparation}

The $\mathrm{ZM}_{\mathrm{FA}}$ was synthesized from thermal and thermo-chemical treated fly ash (FAT) according to the procedure described elsewhere [21]. The raw chicken ESs were dried in the air for a few days, then ground into powder in an agate mortar, and finally calcined at $900{ }^{\circ} \mathrm{C}$ with a rate of $5{ }^{\circ} \mathrm{C} \min ^{-1}$ for $4 \mathrm{~h}$. Thus prepared calcium oxide sample was labeled with $\mathrm{ES}_{900}$. An appropriate quantity of $\mathrm{ES}_{900}$ sample $(x=5$, 10,15 , and $20 \mathrm{wt} \%$ ) was slowly added into $10 \mathrm{wt} \% \mathrm{ZM}_{\mathrm{FA}}$ alcoholic suspension and ultrasonically dispersed in a low-frequency ultrasound device for the time duration of $15 \mathrm{~min}$. After evaporation of alcohol, the obtained catalyst precursor was dried at $110{ }^{\circ} \mathrm{C}$ overnight and finally calcined in the temperature range of $450{ }^{\circ} \mathrm{C}$ to $600{ }^{\circ} \mathrm{C}$ with a rate of $5{ }^{\circ} \mathrm{C} \cdot \mathrm{min}^{-1}$ for $4 \mathrm{~h}$. The resulting supported catalyst denoted as $x \mathrm{CaO} /$ $\mathrm{ZM}_{\mathrm{FA}}$ (where $\times(\mathrm{wt} \%)$ represents a nominal value of $\mathrm{CaO}$ ) was kept in a closed vial placed in a desiccator until the catalytic tests. The scheme of the catalyst synthesis procedure is shown in Fig. 1.

\subsection{Samples characterization}

The crystalline structure of the samples was identified by X-ray diffraction method (XRD, Bruker D8 Endeavor diffractometer) over the angular range of $10-90^{\circ}(2 \theta)$ at a scanning rate $1^{\circ} \mathrm{min}^{-1}$ with a step size of $0.02^{\circ}$ using $\operatorname{CoK} \alpha$ radiation $(\lambda=0.1789 \mathrm{~nm})$. Crystallite size was calculated using the Scherrer equation (Eq. (1)) whereby the peaks selected were at the d-spacing value of $0.4680 \mathrm{~nm}$, and $0.1702 \mathrm{~nm}$, for the zeolite and catalyst, respectively. The crystallinity of the samples was calculated by Eq. (2).

$d=\frac{K \cdot \lambda}{\beta \cdot \cos \theta}$

Crystallinity $=\frac{\text { Area of crystalline peaks }}{\text { Area of all peaks }(\text { crystalline }+ \text { amorphous })} \times 100[\%]$

FT-IR spectra of all samples were recorded using a Shimadzu IRAffinity-1 Fourier transform infrared spectrophotometer (Attenuated Total Reflection-MIRacle 10) in the wavenumber range of 4000-400 $\mathrm{cm}^{-1}$ using 64 scans at $8 \mathrm{~cm}^{-1}$ resolution. The surface morphology was analyzed by a field emission scanning electron microscope (Tescan MIRA3 XMU). Prior to imaging, the samples of dried powder were sputter-coated with a thick, uniform layer of Au/Pd alloy. The specific surface area was calculated from the nitrogen adsorption/desorption isotherms obtained at $77 \mathrm{~K}$ in an ASAP instrument (Micromeritics ASAP 2020) using the BET-equation. Hg-porosimetry measurements were performed in the fully automated conventional apparatus Carlo Erba 2000 porosimeter (pressure range: $0.1-200 \mathrm{MPa}$; pore size (diameter) range: $7.5-15,000 \mathrm{~nm}$ ). The particle size distribution of powder samples was estimated by $\mathrm{Hg}$-porosimetry measurements. The basic strength and basicity were analyzed by a TPD- $\mathrm{CO}_{2}$, Thermo Finningen TPDRO 1100 apparatus equipped with a thermal conductivity detector (TCD) coupled to an MS detector (Thermo Star GSD320). Prior to the desorption, the catalyst precursor $(\sim 100 \mathrm{mg})$ was in situ calcined in the He stream at 
$550{ }^{\circ} \mathrm{C}$ with a rate of $5{ }^{\circ} \mathrm{C} \min ^{-1}$ for $4 \mathrm{~h}$. The $\mathrm{CO}_{2}$ adsorption was done at $60{ }^{\circ} \mathrm{C}$ with a rate of $10^{\circ} \mathrm{C} \mathrm{min}^{-1}$ under the $\mathrm{CO}_{2} / \mathrm{He}$ flow $\left(4.6 \%\right.$ of $\mathrm{CO}_{2}$ in a $\mathrm{CO}_{2} / \mathrm{He}$ mixture, $20 \mathrm{~cm}^{3} \mathrm{~min}^{-1}$ flow rate). In order to remove the physisorbed $\mathrm{CO}_{2}$, the sample was treated in the He stream at $40{ }^{\circ} \mathrm{C}$ for $60 \mathrm{~min}$. Desorption profiles were obtained in the temperature range of 40 to $850{ }^{\circ} \mathrm{C}$ with a rate of $10{ }^{\circ} \mathrm{C} \mathrm{min}^{-1}$.

\subsection{Experimental setup for methanolysis of sunflower oil}

The methanolysis of sunflower oil was carried out in a $250 \mathrm{~mL}$ threeneck round bottom flask coupled to a reflux condenser and equipped with a magnetic stirrer. The reaction vessel was immersed in a glycerol bath placed on a magnetic hotplate stirrer device (IKA C-MAG HS 7) equipped with a temperature controller. Catalytic tests were performed under the following reaction conditions: catalyst concentration of $4 \mathrm{wt} \%$ (relative to the amount of starting oil), reaction temperature of $60{ }^{\circ} \mathrm{C}$, and methanol/oil molar ratio of 12:1. The desired amounts of methanol and catalyst were loaded into the reaction vessel and thermostated at the preset temperature with constant stirring for $30 \mathrm{~min}$. The oil was separately thermostated at the same temperature. After switching off the magnetic hotplate stirrer device, the thermostated oil was poured into the reaction vessel. Thereafter, the device was turned on, the stirring speed was set to $850 \mathrm{rpm}$ and the reaction was timed. The samples were taken from the reaction mixture after the preset time of reaction $(0.5,1$, 1.5, 2, 3, 4, 5, 6, and $7 \mathrm{~h}$ ) and centrifuged (EBA 21, Hettich Zentrifugen) at $10,000 \mathrm{rpm}$ for $10 \mathrm{~min}$ to separate the FAME layer from other reaction products.

\subsubsection{HPLC analysis of FAME}

The FAME samples collected during the catalytic test were analyzed by HPLC (Agilent 1100 Series) equipped with a micro vacuum degasser, binary gradient system, thermostated column compartment, column (Zorbax Eclipse XDB- $\mathrm{C}_{18}, 4.6 \times 150 \mathrm{~mm}, 5 \mu \mathrm{m}$ particle size), and variable wavelength detector using the slightly modified Holčapek method [34]. Before the HPLC analysis, the FAME samples were diluted with a mixture of $n$-hexane and 2-propanol (5:4 v/v) in a ratio of 1:200 and finally filtered through a $0.45 \mu \mathrm{m}$ pore size membrane filter.

\section{Results and discussion}

\subsection{XRD analysis}

X-ray powder diffraction patterns of the support and activated catalysts are shown in Fig. 2a-c. After the thermal and thermo-acid treatment, FA is composed mainly of two crystalline phases: quartz and mullite whereas the other phases like anorthite, aragonite, and hematite were partially removed during the thermo-acid treatment (Fig. 2a). The alkali activation process led to the destruction of the FAT structure into a pure vishnevite type of cancrinite zeolite (PDF\#46-1333). A similar result has been recently obtained using FA from another Serbian power plant [21]. The peaks at $37.5^{\circ}(\mathrm{d}=0.2783 \mathrm{~nm}), 43.7^{\circ}(\mathrm{d}=0.2403 \mathrm{~nm})$, and $63.4^{\circ}(\mathrm{d}=0.1702 \mathrm{~nm})$ of $2 \theta$ angle also confirmed that the lime phase (PDF\#37-1497) was incorporated into the zeolite structure after the ultrasound-assisted dispersion of $\mathrm{CaO}$ and the subsequent thermal activation. A slight increase in the intensities of the $\mathrm{CaO}$ peaks was observed whereas a decrease in the intensities of the zeolite peaks, which can be seen at the zoomed figure in the inset of Fig. $2 b$ and c. The original zeolite structure was mostly preserved despite the treatment, confirming the structural and thermal stability of the synthesized zeolite making it suitable for the reaction under rigorous conditions, which agreed with the TPD- $\mathrm{CO}_{2}$ analysis (Section 3.5 ). The calculated crystallite size of the zeolite was $47.8 \mathrm{~nm}$, which remained unchanged despite the increase in the $\mathrm{CaO}$ concentration. On the other hand, the size of $\mathrm{CaO}$ crystallites deposited on the zeolite was increased significantly from $9.5 \mathrm{~nm}$ for the $5 \mathrm{CaO} / \mathrm{ZM}_{\mathrm{FA}}$ catalyst and to $11.1,21.9$, and $23.4 \mathrm{~nm}$ for the samples containing 10,15 , and $20 \mathrm{wt} \% \mathrm{CaO}$,

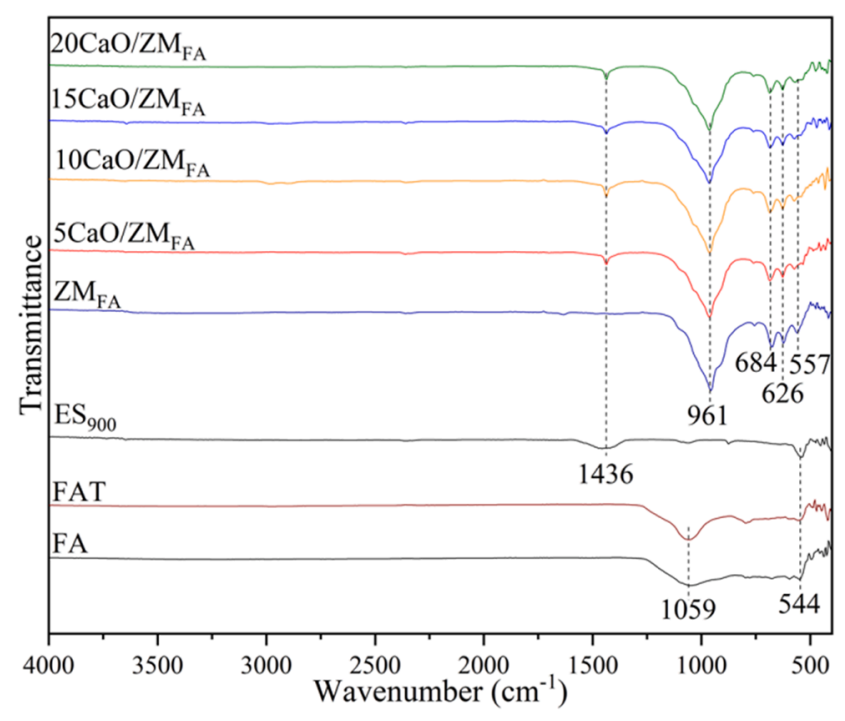

Fig. 3. Infrared spectra of precursors (FA, FAT, and ES 900 ) and activated catalysts $x \mathrm{CaO} / \mathrm{ZM}_{\mathrm{FA}}(x=5,10,15$, and $20 \mathrm{wt} \%$ of $\mathrm{CaO})$.

respectively. This difference in the crystallite size between $\mathrm{CaO}$ and the zeolite facilitates the distribution and contributes to a better dispersion over the zeolite surface and easier accessibility for the reactants. The $\mathrm{MgO}$ crystallites of similar size were observed for the catalytic system containing $\mathrm{MgO}$ that was ultrasonically dispersed over the ceriumdoped MCP-41 nanocatalyst (16.7 nm) [29] and the mixed $\mathrm{CaO}$ and $\mathrm{MgO}$ catalyst $(20-50 \mathrm{~nm})$ [32]. The crystallinity degree of the pure zeolite phases was $81 \%$. An increase in the $\mathrm{CaO}$ concentration slightly increased the sample crystallinity degree to $83 \%$. The obtained crystallinity is similar to that observed for the catalyst obtained from pure chemicals, such as the NaX supported nano-CaO catalyst [24]. The XRD patterns of the catalyst precursor calcined at different temperatures $\left(450-600{ }^{\circ} \mathrm{C}\right.$ ) and the zoomed diffraction at the d-spacing value of $0.1702 \mathrm{~nm}$ with the determined crystallinity and crystallite size are presented in Fig. S1. The higher calcination temperature is beneficial for reducing the crystallite size of $\mathrm{CaO}$. Additionally, the peak intensity characteristic for the lime phase $\left(2 \theta\right.$ of $37.5^{\circ}, 43.7^{\circ}$, and $\left.63.4^{\circ}\right)$ increased up to $550{ }^{\circ} \mathrm{C}$ and then decreased. At calcination temperatures between $450{ }^{\circ} \mathrm{C}$ and $550^{\circ} \mathrm{C}$, the existence of a peak at $2 \theta$ of $34.3^{\circ}(\mathrm{d}=0.3033 \mathrm{~nm})$ can be noted. At $600{ }^{\circ} \mathrm{C}$ the peak disappeared, which could be ascribed to the formation of a calcium silicate compound, such as wollastonite (PDF\#42-547). The calcination at higher temperatures led to grain growth and transformation of the already formed calcium silicate into a more stable, single calcium silicate phase such as larnite (PDF\#70-0388) ( $2 \theta$ of $38.1^{\circ}, \mathrm{d}=0.2741 \mathrm{~nm}$ ) [35]. Both wollastonite and larnite phases were catalytically inactive, however, during the larnite formation, the $\mathrm{CaO}$ obstruction was more pronounced.

\subsection{FT-IR analysis}

The transformation of the surface functional groups during different phases of the synthesis monitored by FTIR spectroscopy is presented in Fig. 3. A wide band located at the wavenumber around $1059 \mathrm{~cm}^{-1}$, associated with an asymmetric stretch mode of $\mathrm{Si}-\mathrm{O}$ vibration in FA, was transformed into a sharper, shifted, and symmetric vibration centered at $961 \mathrm{~cm}^{-1}$ in $\mathrm{ZM}_{\mathrm{FA}}$. This vibration can be ascribed to the frequencies of the $\mathrm{T}-\mathrm{O}(\mathrm{T}=\mathrm{Si}, \mathrm{Al})$ bond in the tetrahedron along with the lines that bonded the tetrahedron oxygen atoms $\left(\mathrm{TO}_{4}\right)^{4-}$ with the central $\mathrm{Si}$ or $\mathrm{Al}$ atoms. The spectra revealed the presence of framework vibrations characteristic for the zeolitic materials, which confirmed that FA conversion into zeolite had been successfully performed [36]. The intensity of the band associated with the vibrations of the T-O bond decreases 

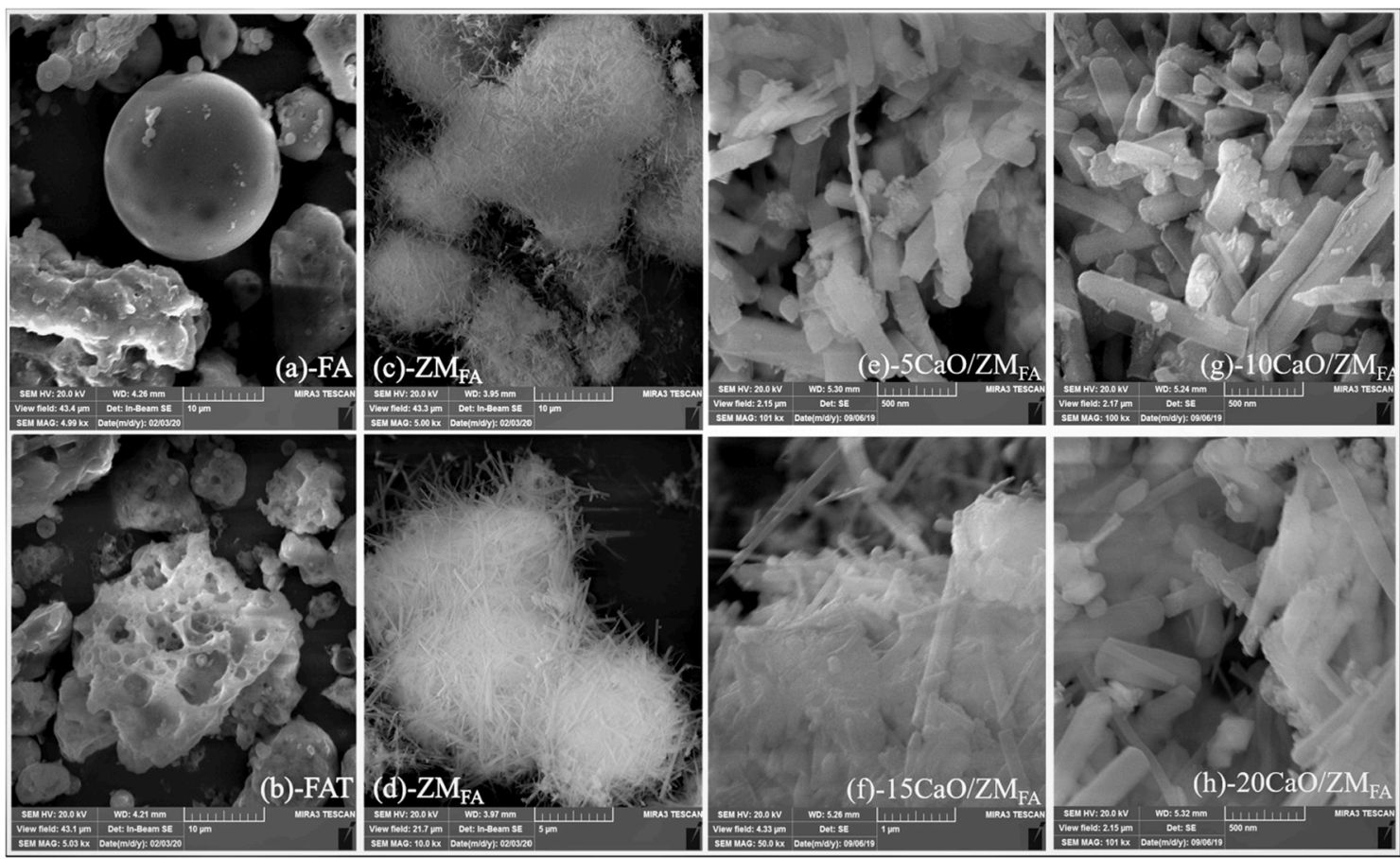

Fig. 4. SEM micrographs of (a-d) precursors (FA, FAT, $\left.\mathrm{ZM}_{\mathrm{FA}}\right)$ and (e-h) activated catalysts $x \mathrm{CaO} / \mathrm{ZM}_{\mathrm{FA}}(x=5,10,15$, and $20 \mathrm{wt} \%$ of CaO).

with increasing the $\mathrm{CaO}$ concentration. During the zeolitization process, a part of the alkali activator $(\mathrm{NaOH})$ was penetrating the glassy phase (quartz) whereas a part reacted with aluminum forming sodiumaluminate, which further penetrated the $\left(\mathrm{SiO}_{4}\right)^{4-}$ skeleton. The absorption bands in the region of $657-684 \mathrm{~cm}^{-1}$ of the $\mathrm{ZM}_{\mathrm{FA}}$ spectrum were assigned to the internal tetrahedron $\mathrm{Si} / \mathrm{Al}-\mathrm{O}$ bending vibrations. The presence of $\mathrm{CaO}$ in the catalyst samples can be associated with the band at $1436 \mathrm{~cm}^{-1}$, which represented an asymmetric stretch of $\mathrm{CO}_{3}^{2-}$ generated due to the absorption of atmospheric $\mathrm{CO}_{2}$ [37]. The other distinctive bands (961 $\mathrm{cm}^{-1}, 684 \mathrm{~cm}^{-1}, 626 \mathrm{~cm}^{-1}$, and $557 \mathrm{~cm}^{-1}$ ) confirmed that the original zeolitic structure was preserved. The FTIR spectra of the $20 \mathrm{CaO} / \mathrm{ZM}_{\mathrm{FA}}$ catalyst calcined at different temperatures are presented in Fig. S2. The intensity of the band at $961 \mathrm{~cm}^{-1}$ increased with increasing the calcination temperature up to $550{ }^{\circ} \mathrm{C}$ and then decreased, which was partially associated with the reaction between calcium and zeolite support [21] or with the possible melting of the glassy phase and a slight decomposition of the zeolite described in Section 3.5. Also, the band related to $\mathrm{CaO}$ at $1436 \mathrm{~cm}^{-1}$ followed the same pattern. In the case of the catalyst sample calcined at $600{ }^{\circ} \mathrm{C}$, the intensity of that band is lower.

\subsection{SEM micrography}

The SEM micrographs of the waste materials (FA and its activated counterpart FAT) and the synthesized products ( $\mathrm{ZM}_{\mathrm{FA}}$ and the catalysts) are shown in Fig. 4. The spherical structure of FA (Fig. 4a) was destroyed during the alkali activation process and converted into a pseudospherical form (Fig. 4b) with a developed pore system, required for an unhindered mass transfer. Due to a relatively high specific surface, FAT is prone to agglomeration, which can be noticed in the inset of Fig. 4b. Subjected to alkali activation, FAT was converted into a uniform, relatively transparent, hexagonal needle-like vishnevite structure, where the needles form woolen-balls like structures. At magnification, higher than $40,000 x$, there is a regular needle structure with different shapes and dimensions. Namely, the needle diameter was approximately between $50 \mathrm{~nm}$ and $200 \mathrm{~nm}$ whereas their length varies from nanometre (approximately between 100 and $500 \mathrm{~nm}$ ) to micrometer (approximately between 1 and $2 \mu \mathrm{m}$ ) scale (Figs. S3 and S4). Such a structure

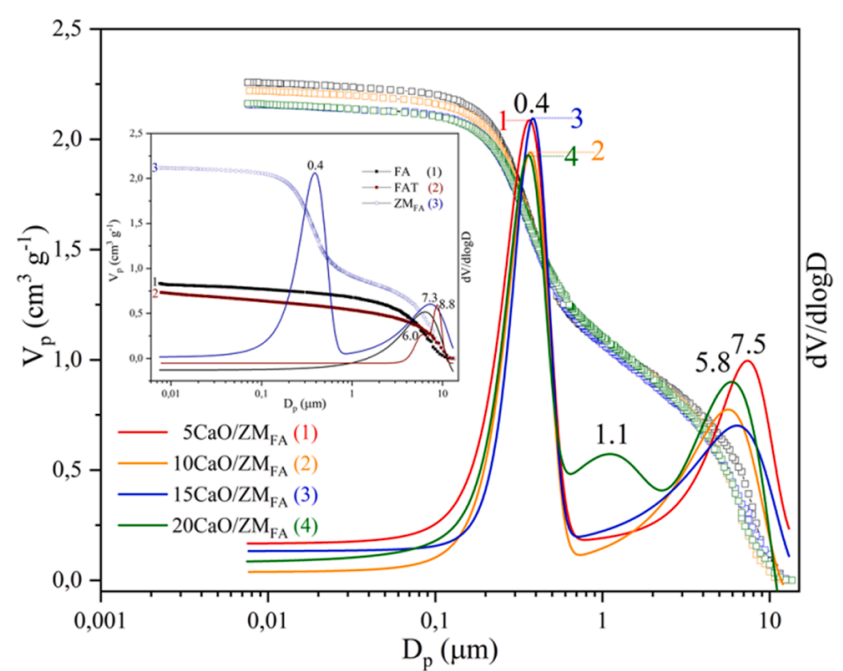

Fig. 5. Pore size distribution of catalyst precursors $\left(\mathrm{FA}, \mathrm{ZM}_{\mathrm{FA}}\right.$, and $\mathrm{ES}_{900}$ ) and activated catalysts $x \mathrm{CaO} / \mathrm{ZM}_{\mathrm{FA}}(x=5,10,15$, and $20 \mathrm{wt} \%$ of $\mathrm{CaO})$.

confirms the adequacy of the selected synthesis conditions, primarily the concentration of the alkali agent, crystallization time, and contactless stirring. Particularly, a relatively high $\mathrm{NaOH}$ concentration $(6.25 \mathrm{M})$ and contactless mixing contribute to the formation of adequate nucleation centers, which lead to the formation of well-defined and uniform crystals. After the ultrasound-assisted dispersion of different $\mathrm{CaO}$ concentrations, the needles became less transparent and shorter, due to the presence of the loaded $\mathrm{CaO}$ and the effects of ultrasound (Fig. 4e-h). At a lower $\mathrm{CaO}$ concentration ( 5 and $10 \mathrm{wt} \%$ ), the needle structure was still noticeable while at higher $\mathrm{CaO}$ concentrations, the needles became stuck together and $\mathrm{CaO}$ filled the space between them. Regularity in the structure of all catalysts with different active species concentrations (Fig. 4e-h) was an indication of the uniform $\mathrm{CaO}$ deposition. 
Table 1

Results of Hg-porosimetry measurements and TPD- $\mathrm{CO}_{2}$ based basic strength.

\begin{tabular}{|c|c|c|c|c|c|c|c|c|c|}
\hline \multirow[t]{3}{*}{ Catalyst } & \multirow{2}{*}{\multicolumn{3}{|c|}{ Hg-porosimetry }} & \multicolumn{4}{|l|}{ Basic sites } & \multirow{2}{*}{\multicolumn{2}{|c|}{ FAME content at reaction time (\%) }} \\
\hline & & & & \multicolumn{3}{|l|}{$\left(\mu \mathrm{mol} \mathrm{g}{ }^{-1}\right)$} & \multirow{2}{*}{$\frac{\left(\mu \mathrm{mol} \mathrm{m}{ }^{-2}\right)}{\text { Total }}$} & & \\
\hline & ${ }^{\mathrm{a}} \mathrm{V}_{\text {total }}$ & ${ }^{\mathrm{b}} \mathrm{P}$ & ${ }^{\mathrm{c}} \mathrm{SA}_{\mathrm{Hg}}$ & Weak $\left(<300^{\circ} \mathrm{C}\right)$ & Medium $\left(300-600^{\circ} \mathrm{C}\right)$ & Strong $\left(>600^{\circ} \mathrm{C}\right)$ & & $1 \mathrm{~h}$ & $2 \mathrm{~h}$ \\
\hline $\mathrm{ES}_{900}$ & 0.449 & 55.2 & 1.5 & 1.5 & 86.6 & 109.8 & 282.7 & 5.1 & 69.4 \\
\hline FA & 0.832 & 13.3 & 15.7 & n.d. & n.d. & n.d. & n. d. & 0.0 & 0.0 \\
\hline FAT & 0.733 & 61.6 & 20.3 & n.d. & n.d. & n.d. & n. d. & 0.0 & 0.0 \\
\hline $\mathrm{ZM}_{\mathrm{FA}}$ & 2.118 & 84.7 & 23.9 & 9.7 & 2.0 & 57.4 & 3.3 & 0.0 & 0.0 \\
\hline $5 \mathrm{CaO} / \mathrm{ZM}_{\mathrm{FA}}$ & 2.258 & 85.8 & 23.3 & 9.6 & 31.5 & 628.8 & 35.1 & 4.4 & 18.7 \\
\hline $10 \mathrm{CaO} / \mathrm{ZM}_{\mathrm{FA}}$ & 2.220 & 84.4 & 22.7 & 6.4 & 54.9 & 756.9 & 49.9 & 9.1 & 32.7 \\
\hline $15 \mathrm{CaO} / \mathrm{ZM}_{\mathrm{FA}}$ & 2.157 & 86.3 & 21.0 & 1.7 & 49.8 & 688.8 & 49.7 & 14.4 & 47.3 \\
\hline $20 \mathrm{CaO} / \mathrm{ZM}_{\mathrm{FA}}$ & 2.162 & 86.5 & 22.6 & 0.0 & 58.8 & 864.5 & 62.0 & 20.7 & 96.5 \\
\hline
\end{tabular}

${ }^{\mathrm{a}}$ Total pore volume $\left(\mathrm{cm}^{3} \mathrm{~g}^{-1}\right) ;{ }^{\mathrm{b}}$ Porosity (vol. \%); ${ }^{\mathrm{c}}$ Specific surface area $\left(\mathrm{m}^{2} \mathrm{~g}^{-1}\right)$, n.d. - not defined

\subsection{Textural properties}

Hg-porosimetry. The cumulative pore volume and pore size distribution (PSD) curves for the tested catalyst samples are shown in Fig. 5. The FA sample had a unimodal PSD (inset in Fig. 5), and its intruded volume increased with increasing the pressure but without a sharp uptake and intensive peak centered about $7.3 \mu \mathrm{m}$.

A similar PSD curve was obtained for the FAT sample, while the thermal and thermo-chemical treatment led to a significant increase in the sample porosity (Table 1). The mercury volume uptake for the $\mathrm{ZM}_{\mathrm{FA}}$ was much sharper than for the FA. In this case, the pore structure was characterized by a clear bimodal PSD with the peaks centered at $0.4 \mu \mathrm{m}$ and $7.3 \mu \mathrm{m}$. The material was retained the bimodal PSD with slightly shifting of the large pore region to a lower diameter during the synthesis process. The total pore volume, $\mathrm{Hg}$-porosimetry-based specific surface area, and porosity of all synthesized samples are shown in Table 1 . The slight and medium porous materials (FA and $\mathrm{ES}_{900}$, respectively) were successfully converted into the highly porous materials with a porosity over $80 \%$, which was almost unchanged after the ultrasound-assisted $\mathrm{CaO}$ dispersion and calcination; the total pore volume stayed also unchanged.

$\mathrm{N}_{2}$-physisorption at $77 \mathrm{~K}$. The nitrogen adsorption-desorption isotherms are presented in Fig. 6a-b. The raw FA with a poorly developed specific surface and pore system was converted into a material with a much larger specific surface area (FAT, $50.7 \mathrm{~m}^{2} \mathrm{~g}^{-1}$ ) by the thermally and thermo-chemical treatments. The obtained adsorption-desorption isotherm for the FAT corresponds to some ordered mesoporous materials. Hysteresis loops can be attributed to H2-type (Fig. 6a), which presents the pore-blocking/percolation in a narrow range of pore necks, or to the cavitation-induced evaporation. Such a pore system, according to the IUPAC international classification [38], is a characteristic of the hydrothermally-treated materials such as high silica materials and different zeolites. That pore system is often unavailable for the deposition of the active catalytic species due to blocking and a relatively small average pore diameter $(4.1 \mathrm{~nm})$. The presence of irregular and small diameter pores are also a problem for the mass transport of large reactant molecules (TAGs and FAMEs). The same was confirmed by the $\mathrm{Hg}$ intrusion porosimetry measurements for two consecutive runs (Run 1 and Run 2), whereby a significant reduction between the two runs in the intruded $\mathrm{Hg}$ volume of $36 \%$ was obvious (Fig. S5). The obtained differences could be ascribed to the interparticle space and special pore shape having a geometry of bottlenecks that did not allow complete emptying of the pores $[39,40]$. The next step of the synthesis, alkali activation, improved the pore network whereby the newly formed pore geometry favored the transport of large organic reactant molecules, without significant limitation. Also, the average pore diameter of the thermo-chemical treated FA was $4.1 \mathrm{~nm}$ whereas for the zeolite and catalysts were $13.5 \mathrm{~nm}$ and $18.2 \mathrm{~nm}$, respectively. The maximum dimension of TAGs molecules that are the largest in the reaction mixture can be calculated on the basis of the largest dimension of the constituents (like glycerol backbone $\sim 0.6 \mathrm{~nm}$ and methyl linoleate $\sim 3$ nm) [28]. The obtained material can be ascribed as a mesoporous (Type IV) with a hysteresis loop classified as H3 type, characteristic for the non-rigid aggregates of the plate-like structures (Fig. 6b). During the $\mathrm{CaO}$ deposition over the $\mathrm{ZM}_{\mathrm{FA}}$, a slight decrease of the specific surface area from $21.2 \mathrm{~m}^{2} \mathrm{~g}^{-1}$ to $14.9 \mathrm{~m}^{2} \mathrm{~g}^{-1}$ was noted with increasing the $\mathrm{CaO}$ loading, but this reduction of the specific surface area was wellcontrolled by the ultrasound-assisted dispersion. Obtained results were in correlation with results of mercury intrusion porosimetry whereby the non-rigid nature with a well-defined pore network was confirmed. The obtained activated catalysts exhibit the same adsorption-desorption isotherms with the same hysteresis loop, like zeolite, confirming that the zeolite structure was preserved without the pore network collapsing.

Particles size distribution. During the synthesis process, the spherical FA particles (mean diameter around $19 \mu \mathrm{m}$ ) were converted into zeolite with a bimodal particle size distribution (mean particle diameter 1.3-18.4 $\mu \mathrm{m}$ ) (Fig. S6a). In the case of the $\mathrm{ES}_{900}$, the bimodal distribution is evident, and the mean diameter is slightly larger than that of zeolite. The ultrasound-assisted $\mathrm{CaO}$ dispersion did not affect the particle size distribution of zeolite as support, i.e. despite the addition of $\mathrm{CaO}$, the particle size of zeolite did not change indicating that $\mathrm{CaO}$ particles are significantly smaller than that of the zeolite (Fig. S6b).

\section{5. $\mathrm{TPD}-\mathrm{CO}_{2}$ analysis}

The TPD- $\mathrm{CO}_{2}$ profiles of the precursors and the synthesized catalysts are shown in Fig. 7a-b. The complex desorption profiles are related to the presence of the basic sites of different strength and their even distribution on the surface of the synthesized zeolite. A low-temperature peak at below $300{ }^{\circ} \mathrm{C}$ can be attributed to the weak basic sites, the temperature peaks between 300 and $600{ }^{\circ} \mathrm{C}$ were related to the medium basic sites whereas the peak above $600{ }^{\circ} \mathrm{C}$ pointed out the strong basic sites $[30,41]$. The values of the basic strength of raw materials, zeolite, and catalysts are presented in Table 1 . The small and broader desorption peaks at $105{ }^{\circ} \mathrm{C}$ for $\mathrm{ZM}_{\mathrm{FA}}, 5 \mathrm{CaO} / \mathrm{ZM}_{\mathrm{FA}}$, and $10 \mathrm{CaO} / \mathrm{ZM}_{\mathrm{FA}}$ indicate the presence of some weak basic sites, corresponding to hydroxyl groups that can form a loose bond with $\mathrm{CO}_{2}$. Furthermore, the peaks of the catalysts in the range from $540{ }^{\circ} \mathrm{C}$ to $730{ }^{\circ} \mathrm{C}$ can be assigned to the medium and strong-strength basic sites of the $\mathrm{Ca}-\mathrm{O}$ ion pairs while the high-strength basic sites correspond to surface $\mathrm{O}^{2-}$ ions. The strong basic sites have a significant Lewis character. The calcined ES (inset in Fig. 7a) exhibited a relatively high number of basic sites, having a weak and especially medium strength. Based on the TPD- $\mathrm{CO}_{2}$ peak width and intensity, the strong basic sites were not uniformly distributed, which can be associated with a non-developed specific surface area of the ES 900 . The ultrasound-assisted dispersion of the calcined ES onto the zeolite support led to a better distribution of basic active sites, confirmed by sharp peaks. A better $\mathrm{CaO}$ dispersion resulted in a significant increase in basicity, especially in the range of strong basic sites. The number of basic sites in the weak and medium regions decreased whereas the number of 

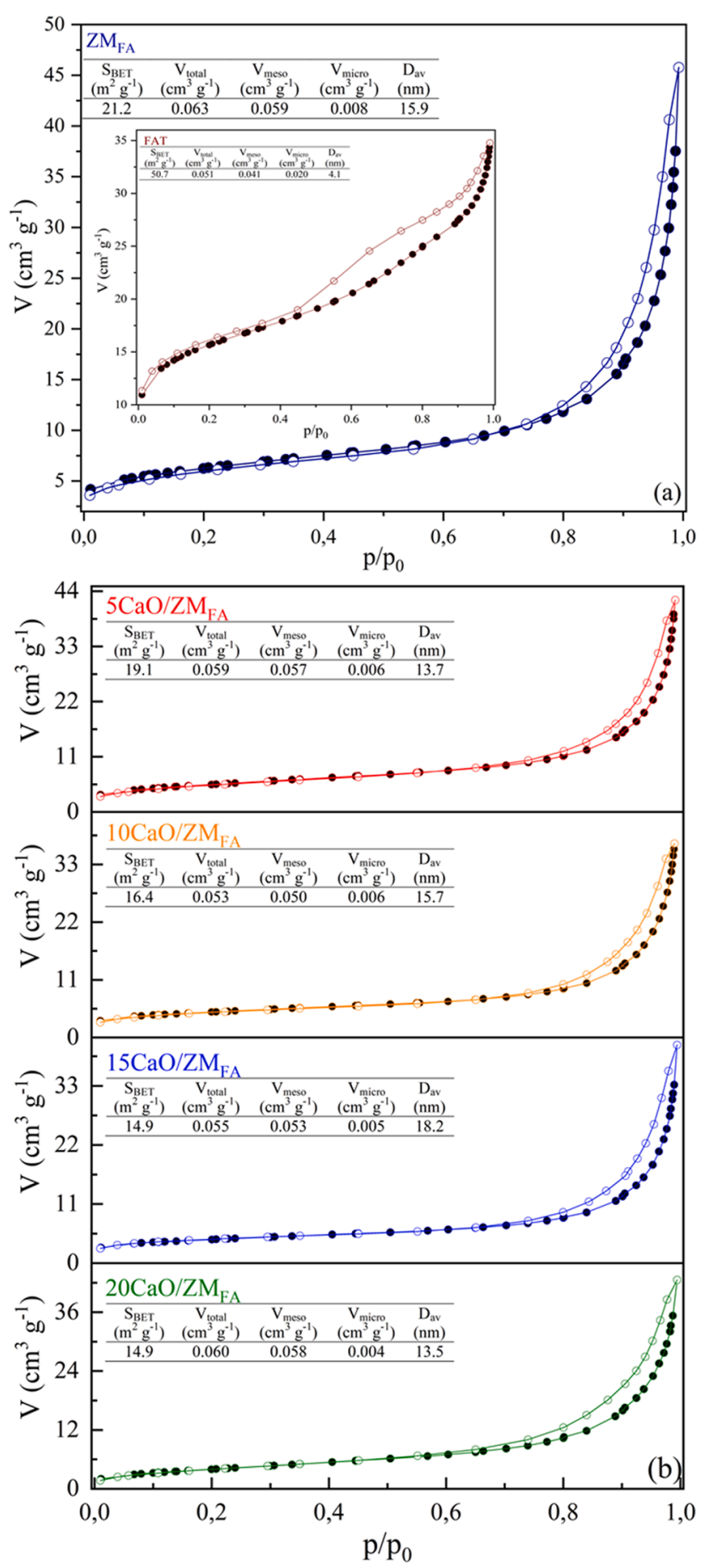

Fig. 6. $\mathrm{N}_{2}$ physisorption isotherms and texture parameters of (a) precursors (FAT, $\mathrm{ZM}_{\mathrm{FA}}$ ) and (b) activated catalysts $x \mathrm{CaO} / \mathrm{ZM}_{\mathrm{FA}}(x=5,10,15$, and $20 \mathrm{wt} \%$ of $\mathrm{CaO})$.

basic sites in the strong region increased with increasing the $\mathrm{CaO}$ content. It is important to note that pure zeolite exhibits low basic characteristics, consequently causing no catalytic activity. A sharp peak of the $\mathrm{ZM}_{\mathrm{FA}}$ on the TPD-CO $\mathrm{CO}_{2}$ profile at $775{ }^{\circ} \mathrm{C}$ (inset in Fig. 7a) could be associated with the decomposition of carbonate that is a part of the cancrinite structure. This statement was confirmed by the TPD- $\mathrm{CO}_{2}$ analysis of the $20 \mathrm{CaO} / \mathrm{ZM}_{\mathrm{FA}}$ catalyst, which was previously treated at $950{ }^{\circ} \mathrm{C}$ (Fig. S7) [42]. In this case, the low-intensity peaks at $91{ }^{\circ} \mathrm{C}$ and $555^{\circ} \mathrm{C}$ can be attributed to free $\mathrm{CaO}$ that has the basic sites in the weak $\left(8.1 \mu \mathrm{mol} \mathrm{g}^{-1}\right)$ and medium $\left(65.0 \mu \mathrm{mol} \mathrm{g}^{-1}\right)$ regions, respectively. A part of $\mathrm{CaO}$ reacted with the glassy zeolite phase at temperatures higher than $800{ }^{\circ} \mathrm{C}$, forming the inactive calcium silicates that do not adsorb $\mathrm{CO}_{2}$. This result also explains the stability of zeolite at high temperatures. Namely, such a synthesized zeolite has significant thermal stability, which generally makes it suitable for catalytic support. Also, the TPD$\mathrm{CO}_{2}$ profiles of the catalyst samples confirmed a strong interaction between $\mathrm{CaO}$ and zeolite.

The relationship between basicity and $\mathrm{CaO}$ content was evident (Table 1). With the increase of the active species concentration from 5 $\mathrm{wt} \%$ to $20 \mathrm{wt} \%$, the basicity also increased from $35.1 \mu \mathrm{mol} \mathrm{m}{ }^{-2}$ to 62.0 $\mu \mathrm{mol} \mathrm{m}{ }^{-2}$. As expected, regarding the chemical composition, the $\mathrm{ZM}_{\mathrm{FA}}$ had a much lower total basicity of only $3.3 \mu \mathrm{mol} \mathrm{m}{ }^{-2}$. Interestingly, the catalyst with $15 \%$ of $\mathrm{CaO}$ showed lower basicity per unit weight than the catalyst with $10 \%$ of $\mathrm{CaO}$, but due to the smaller specific surface, their basicity is almost equal in terms of surface. The calcined ES (pure CaO, ES 900 ) possessed the highest basicity per surface unit, but its basicity per unit weight is several times lower than that of any analyzed catalysts due to its poor surface development.

\subsection{Catalytic test}

The changes in TAG, diacylglycerol (DAG), monoacylglycerol (MAG), and FAME contents during the biodiesel production are shown in Fig. 8. As expected for the heterogeneously catalyzed reaction, FAME content varied sigmoidally with the time. In the initial stage of the reaction, the FAME formation rate increased slowly due to a dominant mass transfer resistance then accelerated rapidly when the chemical reaction has begun to control the overall process, and finally completed after about $2 \mathrm{~h}$. On the other hand, the TAG content decreased complementary with the progress of the reaction. The MAG and DAG contents passed through their maxima but their contents were very low during the overall reaction (maxima MAG and DAG wt $\%$ were 0.6 and 3.0 , respectively).

\subsubsection{Influence of calcination temperature}

The catalysts were thermally activated at different temperatures in the range of $450-600^{\circ} \mathrm{C}$. After calcination, the obtained catalysts were tested in the methanolysis of sunflower oil under the same reaction conditions. The FAME contents after $2 \mathrm{~h}$ and the profiles during the reaction are presented in Fig. 9a. Increasing of calcination temperature up to $550{ }^{\circ} \mathrm{C}$ led to an increase in the catalytic activity (96.5\%). However, at a higher temperature, the catalytic activity significantly decreases (53.5\%), which could be ascribed to the reduction of the number of active species due to the reaction between $\mathrm{CaO}$ and the catalyst support. Namely, it was confirmed that the inactive calcium type zeolite phase could be obtained under such conditions [21]. The FTIR and TPD$\mathrm{CO}_{2}$ analysis confirmed the presence of an inactive calcium silicate phase or non-available calcium in the catalyst calcined at $600{ }^{\circ} \mathrm{C}$. There was also a slight growth of the particles on the surface, which had a negative impact on the activity.

\subsubsection{Influence of concentration of active component}

To study the influence of the chicken ES CaO loading on the catalytic activity, the catalysts with $5,10,15$, and $20 \mathrm{wt} \%$ of $\mathrm{CaO}$ were prepared and tested in the sunflower oil methanolysis. As expected, the $\mathrm{ZM}_{\mathrm{FA}}$ (total basicity of only $3.3 \mu \mathrm{mol} \mathrm{m}{ }^{-2}$ ) showed no activity in the reaction. The FAME content profiles during the reaction with different catalysts are presented in Fig. 9b. An increase in the amount of $\mathrm{CaO}$ increased the reaction rate. With the catalysts with the highest $\mathrm{CaO}$ loading, the reaction equilibrium was reached in $120 \mathrm{~min}$ while in the case of the catalysts with 15,10 , and $5 \mathrm{wt} \%$ of $\mathrm{CaO}$, the reaction was prolonged to $180 \mathrm{~min}, 240 \mathrm{~min}$, and $420 \mathrm{~min}$, respectively. Based on the FAME content profile, it can be concluded that even the $5 \mathrm{CaO} / \mathrm{ZM}_{\mathrm{FA}}$ catalyst would reach the reaction equilibrium and the maximum yield, like other catalysts, but for a significantly longer time. The relationship of the active species content - basicity - catalyst activity was evident (Table 1 \& 

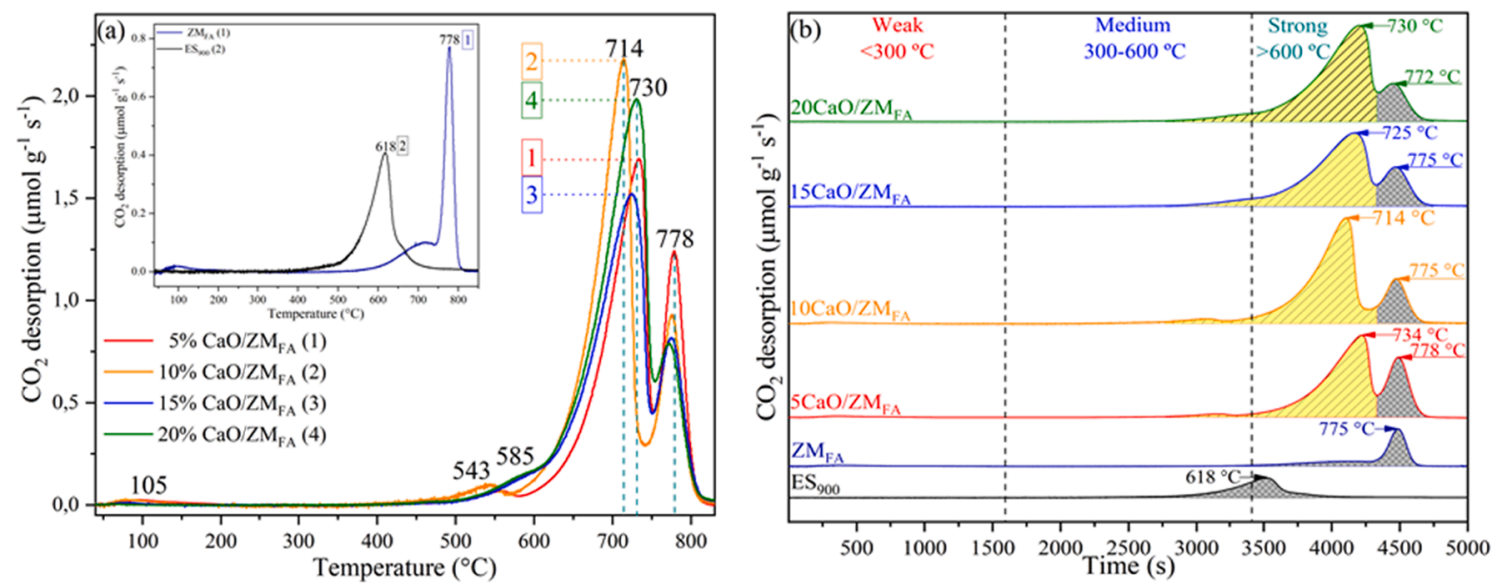

Fig. 7. TPD- $\mathrm{CO}_{2}$ profiles (a) $\mathrm{CO}_{2}$ desorption $v$ s. temperature and (b) $\mathrm{CO}_{2}$ desorption $v$ s. time of precursors (inset (a) $\mathrm{ZM}_{\mathrm{FA}}$, $\mathrm{ES}_{900}$ ) and activated catalysts $x \mathrm{CaO} / \mathrm{ZM}_{\mathrm{FA}}$ $(x=5,10,15$, and $20 \mathrm{wt} \%$ of $\mathrm{CaO})$.

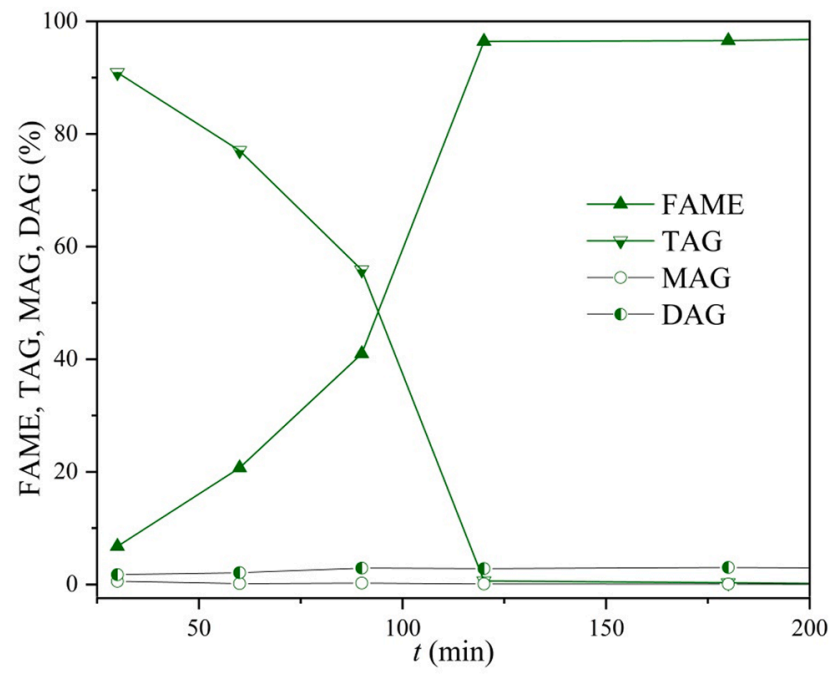

Fig. 8. The variation of the reaction mixture composition with the progress of the sunflower oil methanolysis over the $20 \mathrm{CaO} / \mathrm{ZM}_{\mathrm{FA}}$ catalyst (temperature of $60{ }^{\circ} \mathrm{C}$, methanol/oil molar ratio of $12: 1$, and catalyst concentration of $4 \mathrm{wt} \%$ ).

Fig. 9b). In general, higher basicity leads to higher catalytic activity and a higher FAME yield [43]. With the increase of the active species concentration from $5 \mathrm{wt} \%$ to $20 \mathrm{wt} \%$, the FAME content also increased from $18.7 \%$ to $96.5 \%$ (for $120 \mathrm{~min}$ ). Interestingly, the catalyst with $15 \%$ of $\mathrm{CaO}$ showed higher activity than the catalyst with $10 \%$ of $\mathrm{CaO}$ despite almost the same total basicity. It was explained by the facilitated availability of the active sites to the reacting molecules because of a more developed active specific surface area and favorable porous texture of the $15 \mathrm{CaO} / \mathrm{ZM}_{\mathrm{FA}}$ catalyst.

According to the TPD- $\mathrm{CO}_{2}$ analysis, the number of basic centers of the catalysts increased with the increase in the amount of $\mathrm{CaO}$ in the catalyst, thus increasing the reaction rate. Not only has the amount of the basic sites favored the best catalytic activity, but also its favorable surface texture and morphology, as demonstrated with ES 900 catalyst (neat $\mathrm{CaO}$ ) (Table 1).

\subsubsection{Kinetic parameters of methanolysis reaction}

To better understand the influence of the active sites concentration and the intrinsic properties of the obtained catalyst on its performance in the methanolysis reaction, the experimental FAME data were interpreted kinetically using two kinetic models based on the sigmoidal FAME content profile (Model 1 - the irreversible pseudo-first-order rate laws for both heterogeneous and homogeneous regimes and Model 2 the changing mechanism combined with TAG mass transfer limitations). The analyzed kinetic models have already provided good results in the catalytic systems similar to the present one and are described in detail
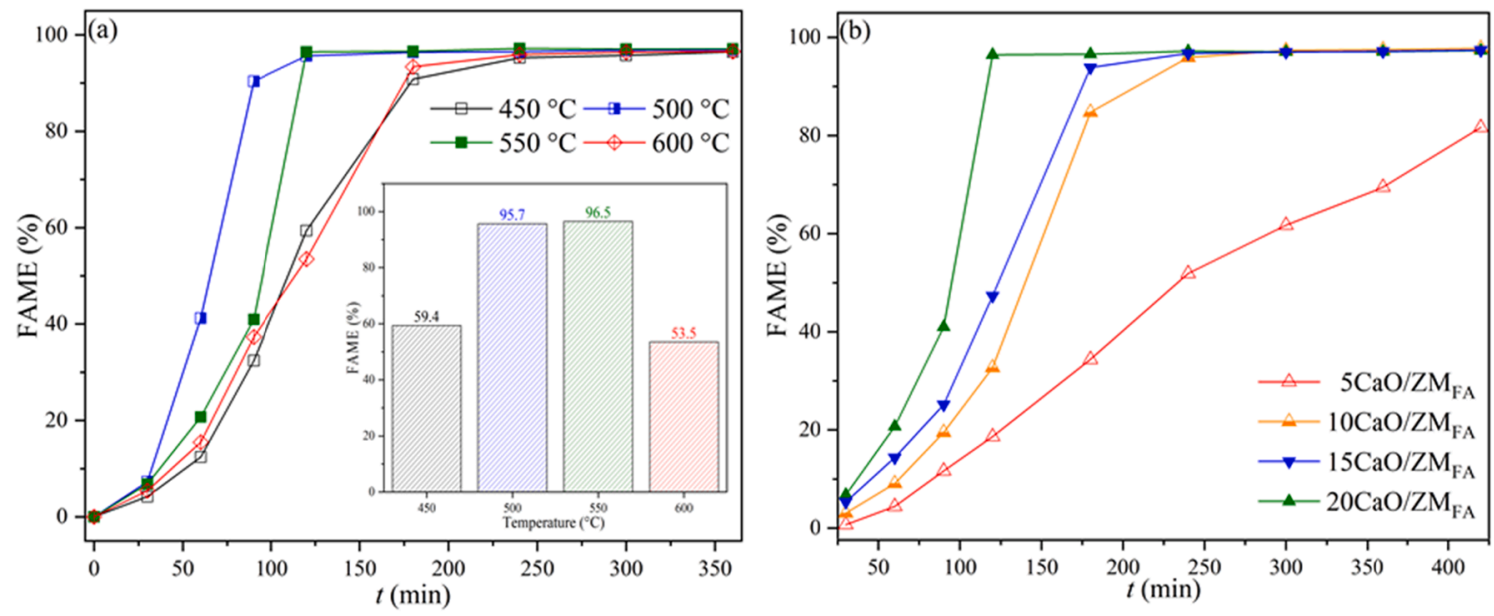

Fig. 9. Influence of (a) catalyst calcination temperature and (b) active species content on FAME content profiles. 
Table 2

The calculated rate constants based on two kinetic models.

\begin{tabular}{|c|c|c|c|c|c|c|c|c|c|c|}
\hline \multirow[t]{2}{*}{ Catalyst } & \multirow[t]{2}{*}{${ }^{\mathrm{a}} \mathrm{T}$} & \multirow[t]{2}{*}{${ }^{\mathrm{b}} \mathrm{MOR}$} & \multirow[t]{2}{*}{${ }^{c} \mathrm{CL}$} & \multicolumn{4}{|l|}{ Model 1} & \multicolumn{2}{|l|}{ Model 2} & \multirow[t]{2}{*}{${ }^{\mathrm{d}} \mathrm{TOF}\left(\mathrm{s}^{-1}\right)$} \\
\hline & & & & $\overline{k_{c} a\left(\min ^{-1}\right)}$ & $\mathrm{R}^{2}$ & $k_{a p p, 1}\left(\min ^{-1}\right)$ & $\mathrm{R}^{2}$ & $\overline{k_{\text {app }, 2}\left(\mathrm{~L} \mathrm{~mol}^{-1} \mathrm{~min}^{-1}\right)}$ & $\mathrm{R}^{2}$ & \\
\hline $5 \mathrm{CaO} / \mathrm{ZM}_{\mathrm{FA}}$ & 60 & $12: 1$ & 4 & 0.0016 & 0.86 & 0.0052 & 0.97 & 0.0064 & 0.92 & $2.6 \cdot 10^{-3}$ \\
\hline $10 \mathrm{CaO} / \mathrm{ZM}_{\mathrm{FA}}$ & & & & 0.0030 & 0.85 & 0.0341 & 0.99 & 0.0176 & 0.99 & $8.6 \cdot 10^{-3}$ \\
\hline $15 \mathrm{CaO} / \mathrm{ZM}_{\mathrm{FA}}$ & & & & 0.0032 & 0.93 & 0.0422 & 0.98 & 0.0214 & 0.98 & $9.4 \cdot 10^{-3}$ \\
\hline $20 \mathrm{CaO} / \mathrm{ZM}_{\mathrm{FA}}$ & & & & 0.0056 & 0.86 & 0.0517 & 0.70 & 0.0270 & 0.98 & $1.5 \cdot 10^{-2}$ \\
\hline
\end{tabular}

${ }^{\text {a }}$ Reaction temperature $\left({ }^{\circ} \mathrm{C}\right.$.

b Methanol to oil molar ratio.

c Catalyst loading (wt $\%)$.

d Turnover frequency.

elsewhere $[44,45]$. The existence of the internal diffusion resistance was determined by calculating the Thiele modulus. The values of Thiele modulus for all catalyst samples $(0.027-0.185)$ were less than 0.4 , indicating that the internal diffusion was negligible. The calculated rate constants for the catalysts with different $\mathrm{CaO}$ loading are presented in Table 2. The volumetric TAG mass transfer coefficient, $k_{\mathrm{c}} a$, (0.0016-0.0056 $\mathrm{min}^{-1}$ ) and the apparent pseudo-first-order rate constant, $k_{\text {app, }, 1},\left(0.0052-0.0517 \mathrm{~min}^{-1}\right)$ increased with increasing the $\mathrm{CaO}$ concentration of the catalysts. In general, the behavior of $k_{\mathrm{c}} a$ can be ascribed to the facilitated diffusion of the reactants towards the welldispersed active sites and the $\mathrm{CaO}$ concentration and basic strength of the catalysts. When the values of different catalysts were assessed, a much lower value was noticed for the catalyst with the lowest $\mathrm{CaO}$ concentration $\left(5 \mathrm{CaO} / \mathrm{ZM}_{\mathrm{FA}}\right)$. This was explained by a significantly lower reaction rate in the second pseudo-homogeneous reaction stage due to an insufficient amount of the active centers at a low concentration of $\mathrm{CaO}$. Fig. 9b shows that the reaction equilibrium was not reached with the $5 \mathrm{CaO} / \mathrm{ZM}_{\mathrm{FA}}$ catalyst for $7 \mathrm{~h}$. The kinetic parameter of Model 2, the apparent pseudo-first-order rate constant, $k_{\mathrm{app}, 2}$, changed similarly to the kinetic parameters of Model 1 and corresponded well to the change

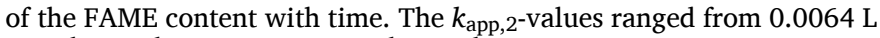
$\mathrm{mol}^{-1} \mathrm{~min}^{-1}$ to $0.0270 \mathrm{~L} \mathrm{~mol}^{-1} \mathrm{~min}^{-1}$. The statistical analysis showed that both models fitted satisfactorily the experimental data, as indicated by relatively low values of the mean relative percentage deviation (MRPD) of $8.6 \%$ and $10.5 \%$, for Model 1 and Model 2, respectively.

The obtained results were in agreement with the similar $\mathrm{CaO} /$ Zeolite catalyst, where the active sites were incorporated in a more complex way $\left(k_{\mathrm{c}} a, k_{\mathrm{app}, 1}\right.$, and $k_{\mathrm{app}, 2}$ were $0.00236 \mathrm{~min}^{-1}, 0.0617 \mathrm{~min}^{-1}$, and $0.0283 \mathrm{~L} \mathrm{~mol}^{-1} \mathrm{~min}^{-1}$, respectively) [21], as well as with some others CaO-based catalysts like pure $\mathrm{CaO}$ [46] or the $\mathrm{CaO} \cdot \mathrm{ZnO}$ mixed oxides [47]. To better understand the correlation between the basicity/basic strength and catalytic activity, the turnover frequency (TOF) was calculated (Table 2). The highest calculated TOF value was $1.5 \cdot 10^{-2} \mathrm{~s}^{-1}$ for $20 \mathrm{CaO} / \mathrm{ZM}_{\mathrm{FA}}$, which correlated to the highest basicity and activity.

\section{Conclusion}

A completely waste-based $\mathrm{CaO} / \mathrm{ZM}_{\mathrm{FA}}$ catalyst was prepared in a twostage process. First, the zeolite support was obtained, and then, the ultrasound-assisted impregnation was used to deposit the active species. Using a miniature autoclave reactor system, lignite FA was converted into a well-crystallized, pure phase of cancrinite zeolite, vishnevite type in an alkali activation process, where the favorable crystallization conditions were enabled by contactless agitation. To shorten the synthesis time and save energy, the ultrasound technique was chosen for the dispersion of calcined chicken ES over the synthesized zeolite. The suitable characteristics (structural, morphological, and textural) of the obtained catalytic support and a method for catalyst synthesis led to the catalyst with a stable structure, whereby the zeolite structure was preserved and the active catalytic species were properly incorporated in the matrix. The synthesized catalyst exhibited remarkable characteristics (well-dispersed active species, high basic strength, and regularly defined pore network) and performances in the biodiesel production under relatively mild conditions (reaction temperature of $60^{\circ} \mathrm{C}$, methanol/oil molar ratio of $12: 1$, the catalyst concentration of $4 \mathrm{wt} \%$ ). The catalyst activation temperature of $550{ }^{\circ} \mathrm{C}$ and the active species concentration of $20 \mathrm{wt} \%$ were proved to be optimal. The highest TAG conversion of $96.5 \%$ was achieved using the $20 \mathrm{CaO} / \mathrm{ZM}_{\mathrm{FA}}$ catalyst for $2 \mathrm{~h}$. The determined rate constants based on two different models corresponded well to the realized catalytic activity and correlated to the $\mathrm{CaO}$ content in the catalyst. The synthesis of this catalyst presents an economic and environmentally friendly process, where the utilization of different waste solids (coal fly ash and chicken ES) leads to the formation of valuable zeolitic products with catalytic activity suitable for biodiesel production.

\section{CRediT authorship contribution statement}

Stefan M. Pavlović: Investigation, Software, Visualization, Writing original draft. Dalibor M. Marinković: Conceptualization, Writing original draft, Project administration. Milan D. Kostić: Formal analysis. Davor R. Lončarević: Formal analysis. Ljiljana V. Mojović: Resources. Miroslav V. Stanković: Supervision, Validation. Vlada B. Veljković: Methodology, Writing - review \& editing.

\section{Declaration of Competing Interest}

The authors declare that they have no known competing financial interests or personal relationships that could have appeared to influence the work reported in this paper.

\section{Acknowledgement}

This work was financially supported by the Ministry of Education, Science and Technological Development of the Republic of Serbia (Grant No. 451-03-68/2020-14/200026 and No. 451-03-68/2020-14/200133 assigned to the Faculty of Technology, Leskovac, University of Niš, researchers' group III 45001).

\section{Appendix A. Supplementary data}

Supplementary data to this article can be found online at https://doi. org/10.1016/j.fuel.2020.119912.

\section{References}

[1] Borowski G, Ozga M. Comparison of the processing conditions and the properties of granules made from fly ash of lignite and coal. Waste Manage 2020;104:192-7. https://doi.org/10.1016/j.wasman.2020.01.024.

[2] Vassilev SV, Vassileva CG. A new approach for the classification of coal fly ashes based on their origin, composition, properties, and behaviour. Fuel 2007;86 (10-11):1490-512. https://doi.org/10.1016/j.fuel.2006.11.020.

[3] Wang N, Sun X, Zhao Q, Yang Y, Wang P. Leachability and adverse effects of coal fly ash: a review. J Hazard Mater 2020;396:122725. https://doi.org/10.1016/j. jhazmat.2020.122725. 
[4] Inada M, Eguchi Y, Enomoto N, Hojo J. Synthesis of zeolite from coal fly ashes with different silica-alumina composition. Fuel 2005;84(2-3):299-304. https://doi. org/10.1016/j.fuel.2004.08.012.

[5] Blissett RS, Rowson NA. A review of the multi-component utilisation of coal fly ash Fuel 2012;97:1-23. https://doi.org/https://doi.org/10.1016/j.fuel.2012.03.024.

[6] Gollakota ARK, Volli V, Shu C-M. Progressive utilisation prospects of coal fly ash: A review. Sci Total Environ 2019;672:951-89. https://doi.org/https://doi.org/ 10.1016/j.scitotenv.2019.03.337.

[7] Li Y, Li L, Yu J. Applications of zeolites in sustainable chemistry. Chem 2017;3(6): 928-49. https://doi.org/10.1016/j.chempr.2017.10.009.

[8] Belviso C, Cavalcante F, Fiore S. Synthesis of zeolite from Italian coal fly ash: Differences in crystallization temperature using seawater instead of distilled water. Waste Manage 2010;30(5):839-47. https://doi.org/10.1016/j. wasman.2009.11.015.

[9] Lee Y-R, Soe JT, Zhang S, Ahn J-W, Park MB, Ahn W-S. Synthesis of nanoporous materials via recycling coal fly ash and other solid wastes: a mini review. Chem Eng J 2017;317:821-43. https://doi.org/https://doi.org/10.1016/j.cej.2017.02.124.

[10] Manique MC, Lacerda LV, Alves AK, Bergmann CP. Biodiesel production using coal fly ash-derived sodalite as a heterogeneous catalyst. Fuel 2017;190:268-73. https://doi.org/10.1016/j.fuel.2016.11.016.

[11] Doyle AM, Alismaeel ZT, Albayati TM, Abbas AS. High purity FAU-type zeolite catalysts from shale rock for biodiesel production. Fuel 2017;199:394-402. https://doi.org/10.1016/j.fuel.2017.02.098.

[12] Gao Y, Jiang J, Meng Y, Aihemaiti A, Ju T, Chen X, et al. A novel nickel catalyst supported on activated coal fly ash for syngas production via biogas dry reforming. Renewable Energy 2020;149:786-93. https://doi.org/10.1016/j. renene.2019.12.096

[13] El Alouani M, Alehyen S, El Achouri M, Taibi M. Comparative study of the adsorption of micropollutant contained in aqueous phase using coal fly ash and activated coal fly ash: kinetic and isotherm studies. Chem Data Collect 2019;23: 100265. https://doi.org/10.1016/j.cdc.2019.100265.

[14] Querol X, Moreno N, Umaña JC, Alastuey A, Hernández E, López-Soler A, et al. Synthesis of zeolites from coal fly ash: an overview. Int J Coal Geol 2002;50(1-4): 413-23. https://doi.org/10.1016/S0166-5162(02)00124-6.

[15] Yang L, Qian X, Yuan P, Bai H, Miki T, Men F, et al. Green synthesis of zeolite 4A using fly ash fused with synergism of $\mathrm{NaOH}$ and Na2CO3. J Cleaner Prod 2019; 212:250-60. https://doi.org/10.1016/j.jclepro.2018.11.259.

[16] Belviso C. State-of-the-art applications of fly ash from coal and biomass: A focus on zeolite synthesis processes and issues. Prog Energy Combust Sci 2018;65:109-35. https://doi.org/https://doi.org/10.1016/j.pecs.2017.10.004.

[17] Chareonpanich M, Namto T, Kongkachuichay P, Limtrakul J. Synthesis of ZSM-5 zeolite from lignite fly ash and rice husk ash. Fuel Process Technol 2004;85(15): 1623-34. https://doi.org/10.1016/j.fuproc.2003.10.026.

[18] Cardoso AM, Paprocki A, Ferret LS, Azevedo CMN, Pires M. Synthesis of zeolite NaP1 under mild conditions using Brazilian coal fly ash and its application in wastewater treatment. Fuel 2015;139:59-67. https://doi.org/https://doi.org/ 10.1016/j.fuel.2014.08.016.

[19] Marrot B, Bebon C, Colson D, Klein JP. Influence of the shear rate during the synthesis of zeolites. Cryst Res Technol 2001;36:269-81. https://doi.org/10.1002/ 1521-4079(200103)36:3<269::AID-CRAT269>3.0.CO;2-Q.

[20] Mainganye D, Ojumu TV, Petrik L. Synthesis of zeolites Na-P1 from South African coal fly ash: effect of impeller design and agitation. Mater (Basel, Switzerland) 2013;6:2074-89. https://doi.org/10.3390/ma6052074.

[21] Pavlović SM, Marinković DM, Kostić MD, Janković-Častvan IM, Mojović LV, Stanković MV, et al. A CaO/zeolite-based catalyst obtained from waste chicken eggshell and coal fly ash for biodiesel production. Fuel 2020;267:117171. https:// doi.org/10.1016/j.fuel.2020.117171.

[22] Algoufi YT, Hameed BH. Synthesis of glycerol carbonate by transesterification of glycerol with dimethyl carbonate over K-zeolite derived from coal fly ash. Fuel Process Technol 2014;126:5-11. https://doi.org/10.1016/j.fuproc.2014.04.004.

[23] Babajide O, Musyoka N, Petrik L, Ameer F. Novel zeolite Na-X synthesized from fly ash as a heterogeneous catalyst in biodiesel production. Catal Today 2012;190(1): 54-60. https://doi.org/10.1016/j.cattod.2012.04.044.

[24] Luz Martínez S, Romero R, López JC, Romero A, Sánchez Mendieta V, Natividad R. Preparation and characterization of $\mathrm{CaO}$ nanoparticles/ $\mathrm{NaX}$ zeolite catalysts for the transesterification of sunflower oil. Ind. Eng. Chem. Res. 2011;50(5):2665-70. https://doi.org/10.1021/ie1006867.

[25] Atadashi IM, Aroua MK, Abdul Aziz AR, Sulaiman NMN. The effects of catalysts in biodiesel production: a review. J Ind Eng Chem 2013;19(1):14-26. https://doi. org/10.1016/j.jiec.2012.07.009.

[26] Sani YM, Daud WMAW, Abdul Aziz AR. Activity of solid acid catalysts for biodiesel production: a critical review. Appl Catal A Gen 2014;470:140-61. https://doi.org/ 10.1016/j.apcata.2013.10.052.

[27] Marwaha A, Dhir A, Mahla SK, Mohapatra SK. An overview of solid base heterogeneous catalysts for biodiesel production. Catal Rev 2018;60(4):594-628. https://doi.org/10.1080/01614940.2018.1494782.
[28] Marinković DM, Avramović JM, Stanković MV, Stamenković OS, Jovanović DM, Veljković VB. Synthesis and characterization of spherically-shaped $\mathrm{CaO} / \gamma-\mathrm{Al}_{2} \mathrm{O}_{3}$ catalyst and its application in biodiesel production. Energy Convers Manage 2017; 144:399-413. https://doi.org/10.1016/j.enconman.2017.04.079.

[29] Dehghani S, Haghighi M. Sono-dispersed MgO over cerium-doped MCM-41 nanocatalyst for biodiesel production from acidic sunflower oil: surface evolution by altering $\mathrm{Si} / \mathrm{Ce}$ molar ratios. Waste Manage 2019;95:584-92. https://doi.org/ 10.1016/j.wasman.2019.05.042.

[30] Sulaiman NF, Hashim ANN, Toemen S, Rosid SJM, Mokhtar WNAW, Nadarajan R, et al. Biodiesel production from refined used cooking oil using co-metal oxide catalyzed transesterification. Renewable Energy 2020;153:1-11. https://doi.org/ 10.1016/j.renene.2020.01.158.

[31] Mansir N, Teo SH, Rabiu I, Taufiq-Yap YH. Effective biodiesel synthesis from waste cooking oil and biomass residue solid green catalyst. Chem Eng J 2018;347: 137-44. https://doi.org/https://doi.org/10.1016/j.cej.2018.04.034.

[32] Foroutan R, Mohammadi R, Esmaeili H, Mirzaee Bektashi F, Tamjidi S. Transesterification of waste edible oils to biodiesel using calcium oxide@ magnesium oxide nanocatalyst. Waste Manage 2020;105:373-83. https://doi.org/ https://doi.org/10.1016/j.wasman.2020.02.032.

[33] Wu L, Wei T, Tong Z, Zou Y, Lin Z, Sun J. Bentonite-enhanced biodiesel production by NaOH-catalyzed transesterification of soybean oil with methanol. Fuel Process Technol 2016;144:334-40. https://doi.org/https://doi.org/10.1016/j. fuproc.2015.12.017.

[34] Stamenkovic O, Lazic M, Todorovic Z, Veljkovic V, Skala D. The effect of agitation intensity on alkali-catalyzed methanolysis of sunflower oil. Bioresour Technol 2007;98(14):2688-99. https://doi.org/10.1016/j.biortech.2006.09.024.

[35] Zdujić M, Lukić I, Kesić Ž, Janković-Častvan I, Marković S, Jovalekić Č, et al. Synthesis of $\mathrm{CaO} \mathrm{SiO}_{2}$ compounds and their testing as heterogeneous catalysts for transesterification of sunflower oil. Adv Powder Technol 2019;30(6):1141-50. https://doi.org/10.1016/j.apt.2019.03.009.

[36] Selim AQ, Mohamed EA, Seliem MK, Zayed AM. Synthesis of sole cancrinite phase from raw muscovite: Characterization and optimization. J Alloys Compd 2018;762: 653-67. https://doi.org/https://doi.org/10.1016/j.jallcom.2018.05.195.

[37] Witoon T. Characterization of calcium oxide derived from waste eggshell and its application as $\mathrm{CO}_{2}$ sorbent. Ceram Int 2011;37(8):3291-8. https://doi.org/ 10.1016/j.ceramint.2011.05.125.

[38] Thommes M, Kaneko K, Neimark AV, Olivier JP, Rodriguez-Reinoso F, Rouquerol $\mathrm{J}$, et al. Physisorption of gases, with special reference to the evaluation of surface area and pore size distribution (IUPAC Technical Report). Pure Appl Chem 2015; 87:1051-69.

[39] Miladinović MR, Zdujić MV, Veljović DN, Krstić JB, Banković-Ilić IB, Veljković VB, et al. Valorization of walnut shell ash as a catalyst for biodiesel production. Renewable Energy 2020;147:1033-43. https://doi.org/10.1016/j. renene.2019.09.056.

[40] Emeruwa E, Jarrige J, Mexmain J, Bernardin M. Application of mercury porosimetry to powder $\left(\mathrm{UO}_{2}\right)$ analysis. J Nucl Mater 1991;184(1):53-8. https:// doi.org/10.1016/0022-3115(91)90532-C.

[41] Roschat W, Phewphong S, Thangthong A, Moonsin P, Yoosuk B, Kaewpuang T, et al. Catalytic performance enhancement of $\mathrm{CaO}$ by hydration-dehydration process for biodiesel production at room temperature. Energy Convers Manage 2018;165:1-7. https://doi.org/10.1016/j.enconman.2018.03.047.

[42] Kazemian H, Naghdali Z, Ghaffari Kashani T, Farhadi F. Conversion of high silicon fly ash to Na-P1 zeolite: alkaline fusion followed by hydrothermal crystallization. Adv Powder Technol 2010;21(3):279-83. https://doi.org/10.1016/j. apt.2009.12.005.

[43] Marinković DM, Miladinović MR, Avramović JM, Krstić IB, Stanković MV, Stamenković OS, et al. Kinetic modeling and optimization of sunflower oil methanolysis catalyzed by spherically-shaped $\mathrm{CaO} / \gamma-\mathrm{Al}_{2} \mathrm{O}_{3}$ catalyst. Energy Convers Manage 2018;163:122-33. https://doi.org/10.1016/j. enconman.2018.02.048.

[44] Kostić MD, Djalović IG, Stamenković OS, Mitrović PM, Adamović DS, Kulina MK, et al. Kinetic modeling and optimization of biodiesel production from white mustard (Sinapis alba L.) seed oil by quicklime-catalyzed transesterification. Fuel 2018;223:125-39. https://doi.org/10.1016/j.fuel.2018.03.023.

[45] Veljković VB, Stamenković OS, Todorović ZB, Lazić ML, Skala DU. Kinetics of sunflower oil methanolysis catalyzed by calcium oxide. Fuel 2009;88(9):1554-62. https://doi.org/10.1016/j.fuel.2009.02.013.

[46] Miladinović MR, Krstić JB, Tasić MB, Stamenković OS, Veljković VB. A kinetic study of quicklime-catalyzed sunflower oil methanolysis. Chem Eng Res Des 2014; 92(9):1740-52. https://doi.org/10.1016/j.cherd.2013.11.023.

[47] Lukić I, Kesić Ž, Maksimović S, Zdujić M, Liu H, Krstić J, et al. Kinetics of sunflower and used vegetable oil methanolysis catalyzed by CaO·ZnO. Fuel 2013;113: 367-78. https://doi.org/10.1016/j.fuel.2013.05.093. 